\title{
Nhận diện quan niệm của sinh viên ngành công tác xã hội và các ngành khác về người nghèo và sự nghèo đói
}

\section{Exploring the perception of poverty among social work and non- social work students in Vietnam}

\author{
Lê Minh Tiến ${ }^{1 *}$ \\ ${ }^{1}$ Trường Đại học Mở Thành phố Hồ Chí Minh, Việt Nam \\ *Tác giả liên hệ, Email: tien.lm@ou.edu.vn
}

\begin{tabular}{ll}
\hline THÔNG TIN & TÓM TÁT \\
\hline
\end{tabular}

DOI: $10.46223 / \mathrm{HCMCOUJS.}$ soci.vi.16.1.1308.2021

Ngày nhận: 11/11/2020

Ngày nhận lại: 27/01/2021

Duyệt đăng: 02/02/2021

\section{Tù̀ khóa:}

người nghèo, sinh viên, nghèo, thái độ, đào tạo công tác xã hội

Keywords:

poor peoples, student, poverty, attitude, social work education
Công tác xã hội $(\mathrm{CTXH})$ là ngành khoa học ứng dụng hướng đến các cá nhân, các cộng đồng yếu thế trong xã hội trong đó có người nghèo. Nghiên cứu này nhằm tìm hiểu quan niệm của sinh viên về người nghèo và sự nghèo đói của sinh viên ngành CTXH trong so sánh với các sinh viên ngành khác đang học tập tại Trường Đại học Mở Thành phố Hồ Chí Minh. Nghiên cứu sử dụng phương pháp định lượng dựa trên bộ tiêu chí đo lường về nhận thức, thái độ đối với nghèo đói do Yun và Weaver (2010) và Atherton, Gemmel, Haagenstad, và Holt (1993) được Việt hóa cho phù hợp với bối cảnh Việt Nam. Mẫu nghiên cứu bao gồm 180 sinh viên năm thứ hai và năm thứ ba, trong đó có 86 sinh viên CTXH và 94 sinh viên thuộc ba ngành Luật, Kinh tế và Ngoại ngữ. Kết quả cho thấy có sự khác biệt có ý nghĩa giữa hai nhóm sinh viên trong nhận định về nguyên nhân nghèo đói do các yếu tố thuộc cá nhân. Tuy nhiên, cả hai nhóm đều tương đồng trong việc xem các yếu tố thuộc cấu trúc xã hội, sự thiếu cơ hội là nguyên nhân của nghèo đói và cả hai nhóm đều có sự thấu cảm cao đối với người nghèo.

ABSTRACT
The goal of the current study was to investigate the social
work and the non - social work students' perception toward the
poor and the poverty. The study uses the quantitative method
based on Attitude Toward Povertyand Poor Peoples (ATP) scale
developed by Yun and Weaver (2010) and Atherton et al. (1993).
The sample was composed of 180 students in Ho Chi Minh City
Open University, including 86 social work students and 94 non-
social work students. The findings of this study highlighted both
causes of poverty - individualistic and structural causes of
poverty. The results may help develop social work education in
the Ho Chi Minh City Open University.

\section{1. Đặt vấn đề}

Tình trạng nghèo đói là một vấn nạn toàn cầu và Việt Nam cũng không là một ngoại lệ. Mặc dù đã đạt được nhiều thành tựu trong công cuộc xóa đói giảm nghèo, được các tổ chức quốc tế đánh giá cao về tốc độ giảm nghèo, nhưng hiện nay, theo số liệu của Ngân hàng Thế giới thì 
vẫn còn gần $10 \%$ dân số Việt Nam, tức khoảng 09 triệu người vẫn còn sống trong tình trạng nghèo đói, trong đó tỷ lệ nghèo đói ở khu vực nông thôn là $13,6 \%$ và đặc biệt là tỷ lệ nghèo nơi nhóm dân tộc thiểu số hiện vẫn ở mức rất cao là $44,6 \%$ so với 3,1\% nơi nhóm người Kinh và người Hoa (World Bank, 2018). Nhìn chung, để có thể giảm nghèo một cách bền vững và hiệu quả, bên cạnh các chính sách xã hội, giáo dục và việc làm mang tính chất vĩ mô của Nhà nước thì sự tham gia của các nhân viên Công tác xã hội $(\mathrm{NVCTXH)}$ là một trong những giải pháp quan trọng trong công cuộc xóa đói giảm nghèo. Bởi vì, theo cách hiểu chung, Công tác xã hội $(\mathrm{CTXH})$ là một hoạt động chuyên nghiệp hướng đến việc hỗ trợ các tầng lớp yếu thế thoát khỏi tình trạng khó khăn của mình. Cụ thể hơn, "CTXH được xem nhu là một nghề mang tính chuyên nghiệp, tồn tại và hoạt động khi xuất hiện nhũng vấn đề cần giải quyết nhu tình trạng nghèo đói, bất bình đẩng giới, và giúp đỡ các thành phần dễ bị tổn thuơng nhu trẻ mồ côi, người khuyết tật, trẻ đương phố, trẻ bị lạm dụng..." (Công tác xã hội, 2019).

Vì vậy, CTXH được xem là một trong những nghề có vai trò quan trọng trong việc trợ giúp các cá nhân, gia đình, cộng đồng và các định chế xã hội nhằm đạt được sự thay đổi về điều kiện kinh tế-xã hội, giải quyết các vấn đề xã hội như nghèo đói, bất bình đẳng xã hội. Tuy nhiên, để các nhân viên $\mathrm{CTXH}$ có thể có những cách làm hiệu quả với các nhóm người yếu thế về kinh tế thì một trong những việc cần làm đó là các nhân viên $\mathrm{CTXH}$ phải có kiến thức, sự hiểu biết và nhận thức chính xác về các nguyên nhân của những vấn đề mà mình quan tâm, trong đó có vấn đề nghèo đói. Quả vậy, nhân viên CTXH chỉ có thể hỗ trợ các cá nhân, các gia đình cũng như các cộng đồng nghèo khi họ nhận diện đúng các yếu tố then chốt dẫn đến tình trạng nghèo đói nơi các cá nhân, nhóm và cộng đồng để từ đó có thể đưa ra cách giải quyết vấn đề một cách thích hợp và hiệu quả.

Tuy nhiên cho đến hiện nay, việc nghiên cứu tìm hiểu xem các nhân viên, sinh viên CTXH nhận định thế nào về tình trạng nghèo đói ở Việt Nam vẫn chưa được thực hiện. Do đó, việc nghiên cứu, tìm hiểu nhận định cũng như thái độ của sinh viên đang học ngành CTXH về các nguyên nhân dẫn đến nghèo đói trong xã hội là một yêu cầu cấp thiết để từ đó, các trường có thể điều chỉnh nội dung, phương pháp đào tạo phù hợp hơn để có thể giúp các em sinh viên sau khi ra trường có thể có những cách làm hiệu quả trong việc trợ giúp, hỗ trợ các cộng đồng nghèo, vốn là một trong những đối tượng làm việc chủ yếu của các nhân viên CTXH.

\section{Tổng quan tình hình nghiên cứu trong nước và ngoài nước}

Công tác xã hội $(\mathrm{CTXH})$ thường được hiểu như là hoạt động chuyên nghiệp nhằm trợ giúp các cá nhân, gia đình và xã hội phát triển. Cụ thể là theo định nghĩa của Liên đoàn Công tác Xã hội thế giới năm 2014 thì: "CTXH vìa là một nghề mang tính thưc hành vì̀a là một lĩnh vục học thuật nhằm thúc đẩy cho sụ thay đổi, sự phát triển và sự cố kết của xã họi, trao quyền và giải phóng cho con người. Các nguyên tắc về công bằng xã họi, quyền con người, trách nhiệm tập thể và tôn trọng sự đa dạng là các nguyên tắc nền tảng của nghề CTXH. Được củng cố bởi các lý thuyết về công tác xã họi, khoa học xã hội, nhân văn và kiến thức bản địa, CTXH tiếp cận con người và các cơ cấu để giải quyết các thách thức của cuộc sống và nâng cao phúc lợi”" (IFSW, 2014). Với định nghĩa trên, chúng ta thấy $\mathrm{CTXH}$ vừa là một nghề thực hành vừa là một lĩnh vực học thuật, do đó, để có thể góp phần thúc đẩy cho sự phát triển của xã hội, giúp đỡ và hỗ trợ cho những người cũng như các gia đình đang đối mặt với khó khăn trong cuộc sống, những nhóm người yếu thế và đặc biệt là những người nghèo và các gia đình nghèo như quan niệm của Hiệp hội Nhân viên CTXH Mỹ thì "nhũng nổ lực thay đổi xã hội của NVCTXH tập trung chủ yếu vào các vấn đề nghèo đói, thất nghiệp, phân biệt đối xủ và các hình thức bất công xã hội khác", (NASW, 2017) đòi hỏi sinh viên ngành CTXH phải có cách hiểu đầy đủ, toàn diện về vấn đề nghèo đó để từ đó có thể tìm ra các phương thức làm $\mathrm{CTXH}$ cá nhân, gia đình thích hợp để hỗ trợ những đối tượng này. 
Thế nhưng hiện nay các nghiên cứu trong nước liên quan đến nhận thức, thái độ của những người học và làm CTXH về các vấn đề xã hội còn khá hạn chế. Chúng ta có thể điểm qua một số nghiên cứu liên quan đến nhận thức, thái độ của sinh viên, nhân viên CTXH như sau:

Trước hết là nghiên cứu của Dang (2013) về nhận thức hành vi nghề nghiệp của nhân viên xã hội. Tác giả đã khảo sát nhận thức về nghề nghiệp của nhân viên xã hội tại Trung tâm Bảo trợ xã hội tỉnh Lâm Đồng và Trung tâm 05-06, huyện Đức Trọng, tỉnh Lâm Đồng. Trong nghiên cứu này, tác giả đã thực hiện 20 cuộc phỏng vấn sâu với các nhân viên xã hội (08 nhân viên xã hội chuyên nghiệp và 12 nhân viên xã hội bán chuyên nghiệp) nhằm phân tích các khía cạnh nhận thức của nhân viên xã hội về công việc, về thân chủ và về bản thân với tư cách là nhân viên xã hội và những yếu tố ảnh hưởng đến những vấn đề đó.

Nghiên cứu của T. T. Le (2016) về nhận thức của sinh viên ngành CTXH về tiếp cận và huy động nguồn lực cộng đồng có thể được xem như là nghiên cứu đầu tiên theo hướng nghiên cứu này. Theo các tác giả, nhận thức của sinh viên $\mathrm{CTXH}$ về tiếp cận cộng đồng và huy động nguồn lực cộng đồng của sinh viên công tác xã hội còn rất hạn chế. Điều này còn do nhiều yếu tố cả chủ quan từ phía sinh viên và những yếu tố khách quan như điều kiện, tổ chức, đào tạo và trang thiết bị học tập cũng như môi trường tiếp cận cộng đồng.

Xét trên bình diện quốc tế, việc nghiên cứu nhận thức, thái độ của sinh viên về nghèo đói và người nghèo đã được thực hiện tương đối nhiều.

Trước hết là nghiên cứu của Schwartz và Robinson (1991) so sánh các quan niệm của 119 sinh viên CTXH tại các trường Đại học vùng Trung Tây của Mỹ. Các sinh viên được phân ra thành ba nhóm: Nhóm mới bắt đầu học CTXH, Nhóm đã học xong các khóa dẫn nhập CTXH và Nhóm học chuyên sâu về CTXH. Kết quả cho thấy cái nhìn của sinh viên CTXH về nghèo đói là phù hợp với các giá trị cốt lõi của ngành $\mathrm{CTXH}$, mặc dù có sự khác biệt trong nhìn nhận về các lý do giữa các nhóm. Nghiên cứu khác của Rosenthal (1993) về niềm tin và nhận thức của sinh viên CTXH về người nghèo. Kết quả khảo sát trên một mẫu gồm 137 sinh viên tại ba trường thuộc vùng New York (Mỹ) cho thấy các sinh viên có nhận thức rất sai lầm về tình trạng kinh tế của người nghèo và các sinh viên cũng cho rằng tình trạng nghèo đói không phải là một hiện tượng phổ biến. Để khắc phục tình trạng này, tác giả cho rằng trong việc đào tạo $\mathrm{CTXH}$, điều quan trọng không phải chỉ là cung cấp các sự kiện, các số liệu mà còn phải giải thích bối cảnh và ý nghĩa của các số liệu ấy.

Thái độ của NVCTXH đối với nghèo đói cũng được nghiên cứu thông qua công trình do Rehner, Ishee, Salloum, và Velasques thực hiện vào năm 1997. Trong công trình này, các tác giả đã tiến hành phân tích thái độ về nghèo đói và người nghèo thông qua bộ tiêu chí đo lường thái độ về nghèo đói do Atherton và cộng sự phát triển vào năm 1993 trên một mẫu gồm 186 NVCTXH tại Mississippi (Mỹ). Kết quả cho thấy, những NVCTXH lớn tuổi và có thâm niên cao trong thực hành nghề $\mathrm{CTXH}$ thì có thái độ tích cực về nghèo và người nghèo hơn là các NVCTXH trẻ, chưa có nhiều thâm niên thực hành nghề.

Dựa trên thang đo về thái độ đối với vấn đề nghèo đói của Feagin (Feagin's Poverty Scale), Sun (2001) đã tiến hành nghiên cứu so sánh cái nhìn của hai nhóm sinh viên CTXH và không phải sinh viên $\mathrm{CTXH}$ của một trường đại học tại vùng Tây Nam của Mỹ. Kết quả cho thấy có sự khác biệt trong nhận thức về nghèo đó giữa các nhóm sinh viên mà theo đó, nhóm sinh viên CTXH là nữ và sinh viên $\mathrm{CTXH}$ da trắng thì cho rằng các nhân tố cấu trúc là nguyên nhân chủ yếu của nghèo đói. Trong khi đó, nhóm sinh viên nam $\mathrm{CTXH}$ và không phải da trắng thì cho rằng nghèo đói là kết quả của các nhân tố cấu trúc lẫn các nhân tố thuộc cá nhân. Các sinh viên thuộc các ngành khác cũng không cho rằng nghèo đói là kết quả của các nhân tố cá nhân như kỳ vọng.

Về thái độ đối với người nghèo và những đặc trưng của cái nghèo, kết quả nghiên cứu theo 
khuynh hướng tâm lý học do Cozzarelli, Wilkinson, và Tagler (2001) thực hiện trên nhóm sinh viên tại Đại học Midwestern University (Mỹ) cho thấy, thái độ của sinh viên đối với tầng lớp nghèo là tiêu cực hơn so với thái độ của họ đối với tầng lớp trung lưu. Đồng thời, phần lớn sinh viên cũng cho rằng người nghèo là do những nguyên nhân thuộc về cá nhân của người nghèo như lười biếng, thiếu đạo đức, thiếu giáo dục...

Castillo và Becerra (2012) đã tiến hành nghiên cứu nhằm tìm hiểu nhận thức của sinh viên CTXH về nghèo đói và các chính sách an sinh xã hội tại Mỹ. Qua khảo sát 264 sinh viên CTXH, các tác giả kết luận rằng các yếu tố giới, sắc tộc, trình độ, việc đã sống hoặc đã đi du lịch các nước đang phát triển và điều kiện kinh tế-xã hội của sinh viên có tác động đến nhận thức, thái độ của họ đối với vấn đề nghèo đói và các chính sách xã hội.

Năm 2016, Hill, Toft, Garrett, Ferguson, và Kuechler cho công bố kết quả nghiên cứu về thái độ của các sinh viên đang theo học chương trình Cao học về CTXH lâm sàng (Clinical MSW) tại Minnersota (Mỹ). Kết quả nghiên cứu trên mẫu gồm 337 sinh viên cho thấy đa số sinh viên cho rằng các yếu tố thuộc cấu trúc xã hội là nguyên nhân dẫn đến nghèo đói hơn là các yếu tố thuộc cá nhân.

Gần đây, Hamilton và Daughtry (2017) đã tiến hành so sánh cách nhìn về nghèo đói giữa nhóm sinh viên CTXH học theo lối truyền thống (học tại trường) và nhóm sinh viên CTXH học qua mạng (Online). Kết quả cho thấy nhóm sinh viên học qua mạng quan niệm nghèo đói là kết quả của những nhân tố mang tính cá nhân nhiều hơn so với nhóm học theo kiểu truyền thống.

Nhìn chung trên bình diện thế giới, các nghiên cứu về nhận thức, thái độ của sinh viên ngành CTXH về nghèo đói đã có những khám phá đáng chú ý. Phần lớn các kết quả cho thấy cách hiểu tương đối không chính xác về các nguyên nhân của nghèo đói và điều này đặt ra những yêu cầu về việc cải tiến chương trình, cách thức đào tạo sinh viên chuyên ngành này.

\section{Mục tiêu của đề tài}

Một trong những mục tiêu đào tạo ngành $\mathrm{CTXH}$ của Trường Đại học Mở Thành phố Hồ Chí Minh mà theo đó, đào tạo sinh viên $\mathrm{CTXH}$ "Có kiến thức chuyên ngành để có huớng giải quyết thích hợp đối với các vấn đề liên quan đến tọi phạm, các vấn đề của trẻ, các vấn đề của gia đình, nghèo đói, người khuyết tật, người cao tuổi, nạn nhân bi bạo hành, người làm mại dâm, người nhiễm HIV..." (Trường Đại học Mở Thành phố Hồ Chí Minh, 2017). Để có thể góp phần giải quyết các vấn đề xã hội như nghèo đói chẳng hạn, sinh viên trước hết cần có nhận thức phù hợp trước vấn đề mà mình quan tâm. Do đó, đề tài nghiên cứu này nhằm vào ba mục tiêu chính như sau:

Tìm hiểu nhận thức, cách nhìn nhận cũng như thái độ của sinh viên CTXH về hiện tượng nghèo đói trong so sánh với những sinh viên ngành khác về hiện tượng nghèo đói trong xã hội nhằm đánh giá xem liệu sinh viên $\mathrm{CTXH}$ có nhận thức khác biệt về tình trạng nghèo đói trong xã hội so với các sinh viên thuộc các ngành khác vốn không được trang bị nhiều các kiến thức liên quan đến các vấn đề xã hội.

- Phân tích các nhân tố ảnh hưởng đến nhận thức của sinh viên về nghèo đói;

- Đề xuất các hàm ý ứng dụng vào việc giảng dạy, đào tạo sinh viên CTXH tại Khoa Xã hội học - Công tác xã hội - Đông Nam Á.

\section{Co’ sở lý luận}

\subsection{Về khái niệm nghèo}

Khi nghiên cứu về vấn đề nghèo đói (Poverty), các nhà nghiên cứu gần như đều đồng ý 
rằng không có một định nghĩa duy nhất đúng về nghèo, và do đó, cũng không có một phương pháp hoàn hảo nào để đo lường được nó. Các tổ chức quốc tế cũng thường có cách định nghĩa tương đối khác nhau về nghèo. Chẳng hạn trong báo cáo "Chiến thắng sụ nghèo đói của con người” (Vaincre la pauvreté humaine) vào năm 2000 của Chương trình Phát triển Liên Hiệp Quốc (UNDP) đã định nghĩa: "Người nghèo là người có thu nhập không đủ để thỏa mãn nhũng nhu cầu thực phẩm căn bản" (Benicourt, 2001). Đối với Ngân hàng Thế giới (WB) thì: "Nghèo là tình trạng thiếu thốn ở nhiều phuơng diện nhu thu nhập hạn chế, thiếu co hội tạo thu nhập, thiếu tài sản để đảm bảo tiêu dùng trong nhũng lúc khó khăn, dễ bi tổn thương trước nhũng đột biến bất lợi..." (World Bank, 2003). Còn theo định nghĩa của Liên hiệp quốc (UN): "Nghèo bao gồm nhiều nhiều cạnh hơn là chi việc thiếu thu nhập hay các nguồn lực sản xuất cần thiết để đảm bảo sinh kế bền vũng. Nhũng biểu hiện của nghèo bao gồm đói và suy dinh duỡng, bị hạn chế tiếp cận giáo dục và các dịch vu co bản khác, bị phân biệt đối xủ và loại trù xã hội cũng nhu thiếu co hội tham gia vào quá trình ra quyết định" (United Nations, n.d.).

Trong khái niệm nghèo đói, các nhà nghiên cứu còn phân thành hai dạng khác nhau đó là nghèo tuyệt đối (absolute poverty) và nghèo tương đối (relative poverty). Nghèo tuyệt đối là tình trạng mà các cá nhân có thu nhập dưới ngưỡng nghèo hay chuẩn nghèo (line of poverty). Chuẩn nghèo là ngưỡng thu nhập tối thiểu để “đáp ứng nhu cầu cơ bản" về dinh dưỡng, tức là dưới mức thu nhập để thỏa mãn những nhu cầu thực phẩm căn bản. Theo ngưỡng nghèo của Ngân hàng Thế giới công bố năm 2015, ngưỡng nghèo chung trên thế giới là 1,90 USD/người/ngày, tức đây là mức thu nhập đủ để đáp ứng 1.800 calorie/ngày. Điều cần lưu ý là ngưỡng nghèo luôn thay đổi theo thời gian do sự biến đổi về tình hình kinh tế-xã hội của quốc gia, và mỗi quốc gia, mỗi khu vực sẽ có ngưỡng nghèo riêng. Chẳng hạn đối với Việt Nam, chuẩn nghèo được phân thành hai loại gồm chuẩn nghèo cho vùng nông thôn và chuẩn nghèo cho vùng đô thị. Theo Quyết định số 59/2015/QĐ-TTg do Thủ tướng Chính phủ ký ngày 19 tháng 11 năm 2015, chuẩn nghèo về của Việt Nam là 900.000 đồng/người/tháng ở khu vực thành thì và 700.000 đồng/người/tháng ở khu vực nông thôn. Như vậy những người ở nông thôn và đô thị có thu nhập dưới chuẩn nghèo ấy thì được gọi là nghèo tuyệt đối hay nghèo cùng cực (extreme poverty).

Nghèo tương đối là những người có thu nhập không đủ để thỏa mãn những nhu cầu phi dinh dưỡng căn bản như quần áo, nhà ở, năng lượng, nước sạch. Thông thường, nghèo tương đối chỉ tình trạng thiếu hụt các nguồn lực nơi các cá nhân hoặc nhóm trong so sánh với các cá nhân hoặc nhóm khác trong xã hội. Điều đó có nghĩa nghèo tương đối là tình trạng một bộ phận dân cư có mức sống dưới mức sống trung bình của cộng đồng tại địa phương được xem xét.

Những định nghĩa về nghèo như trên chỉ chú trọng đến khía cạnh thu nhập và do đó là không toàn diện và không giúp hiểu được tình trạng của người nghèo, vì vậy hiện nay các tổ chức quốc tế cũng như Việt Nam bắt đầu xem xét nghèo đói ở nhiều khía cạnh hơn là chỉ thu nhập. Từ đó xuất hiện khái niệm "nghèo đa chiều” (multidimensional poverty). Sở dĩ có quan niệm nghèo đa chiều là bởi vì nghèo không hẳn chỉ là đói ăn, thiếu uống, thiếu các điều kiện sống và các điều kiện sinh hoạt khác mà còn bao hàm những rào cản khác trong việc tiếp cận các dịch vụ khác như thông tin, giáo dục, nhà ở... Như vậy, việc đánh giá nghèo dựa trên nhiều chiều cạnh khác nhau sẽ giúp nhận diện chính xác hơn về tình trạng nghèo. Theo chuẩn nghèo đa chiều của Việt Nam được công bố năm 2015, ngoài sự thiếu hụt về thu nhập theo chuẩn nghèo, người nghèo còn là người thiếu hụt từ ba trong số năm dịch vụ xã hội cơ bản là y tế, giáo dục, nhà ở, nước sạch và vệ sinh, thông tin. Các dịch vụ xã hội cơ bản ấy được đo lường thông qua mười chỉ số: tiếp cận các dịch vụ y tế, bảo hiểm y tế, trình độ giáo dục của người lớn, tình trạng đi học của trẻ em, chất lượng nhà ở, diện tích nhà ở bình quân đầu người, nguồn nước sinh hoạt, hố xí/nhà tiêu hợp vệ sinh, sử dụng dịch vụ viễn thông, tài sản phục vụ tiếp cận thông tin. 


\subsection{Các lối giải thích về nghèo đói}

Trong xã hội loài người, nghèo đói là một trong những vấn đề phổ biến và có tính "lâu bền" nhất và do đó, đây là vấn đề nhận được nhiều sự chú ý của các nhà nghiên cứu từ xã hội học, nhân học cho đến kinh tế học. Trong lý giải về vấn đề nghèo đói, người ta thấy tựu trung có ba lối lý giải khác nhau về hiện tượng này: lối lý giải mang tính cá nhân, lối lý giải mang tính văn hóa và lối lý giải mang tính cơ cấu.

Trước hết là lối lý giải mang tính cá nhân về nghèo đói (Individualistic explanation). Lối giải thích mang tính cá nhân về nghèo đói có lẽ xuất phát từ cách nhìn của nhà xã hội học Anh là Herbert Spencer vốn được xem là một trong những gương mặt tiêu biểu của "Chủ nghĩa Darwin xã hội” (Social darwinism) vốn cho rằng xã hội loài người cũng tiến hóa như thế giới tự nhiên mà ở đó, chỉ những kẻ mạnh nhất mới sống sót (survival of the fittest). Từ đó ông cho rằng luật cho người nghèo (poor laws), giúp đỡ cho người nghèo là mâu thuẫn với luật tự nhiên (natural law). Như ông viết: "Nếu họ (người nghèo) đủ mạnh để sống thì ho sống, ho có thể sống. Nếu ho không đủ mạnh để sống thì họ chết, và tốt hơn là họ nên chết” (Roark, 2004, p. 25). Từ cách nhìn mang tính "tiến hóa luận" (evolutionism) như trên dẫn đến cách nhìn về nghèo đói như là một hiện tượng mang tính cá nhân (individual phenomenon), tức là sự nghèo đói là kết quả của những yếu tố thuộc cá nhân, chính bản thân cá nhân phải chịu trách nhiệm cho sự nghèo đói của mình. Theo Rank (1994), chính thái độ và động cơ của cá nhân là nguyên nhân dẫn tới nghèo đói, cụ thể hơn, chính sự lười biến, thiếu hiểu biết, thiếu động lực làm việc, thiếu học hỏi của người nghèo chính là nguyên nhân làm cho họ nghèo. Với cách nhìn về nghèo đói như là hệ quả của các yếu tố thuộc cá nhân, các nghiên cứu theo khuynh hướng này thường thu thập những thông tin liên quan đến những đặc trưng cá nhân như chủng tộc, giới tính, tình trạng hôn nhân, sức khỏe, trình độ học vấn... để lý giải cho tình trạng nghèo đói của các cá nhân trong xã hội.

Lối lý giải mang tính văn hóa về nghèo đói (Cultural explanation) lại nhìn nghèo đói như là kết quả của những yếu tố thuộc về nền văn hóa. Điển hình cho lối lý giải này là Lewis (1978) xem nền tảng văn hóa của cá nhân là yếu tố dẫn đến nghèo đói bởi văn hóa tác động đến giá trị sống, thái độ sống và ứng xử của cá nhân. Trong công trình "Nền văn hóa nghèo đói - Nhũ̃ng đứa con của Sanchez" của mình, Lewis cho rằng người nghèo phát triển một nền văn hóa riêng biệt khiến họ bị dính chặt vào tình trạng nghèo. Nền văn hóa của người nghèo gồm những đặc điểm như thiếu khả năng hoạch định tương lai, thiếu cái nhìn dài hạn mà cụ thể là họ thường mua thực phẩm tiêu dùng hằng ngày mà ít khi tích trữ để tiêu dùng lâu ngày. Người nghèo cũng thường có tâm trạng thờ ơ, ngờ vực trước người khác, luôn có cảm giác bị gạt ra bên lề, cảm giác tuyệt vọng, cảm giác phụ thuộc và bị xa lánh. Người nghèo cũng cảm thấy mình như người xa lạ trong đất nước của họ và nghĩ rằng những định chế hiện hữu không đáp ứng được lợi ích và nhu cầu của họ. Cùng với đó là cảm giác bất lực, thấy mình thấp kém và cảm giác tự ti cũng ngự trị nơi người nghèo. Những người nghèo cũng ít có ý thức về lịch sử, họ chỉ biết đến những nỗi khổ, những điều kiện sống và lối sống của chính họ mà thôi.

Cũng trong cách nhìn mang tính văn hóa về nghèo đói, Bourdieu (1990) giải thích sự nghèo đói là do sự thiếu vốn văn hóa (cultural capital) nơi các cá nhân. Theo Bourdieu, vốn văn hóa là toàn bộ những nguồn lực văn hóa-xã hội như các giá trị, các niềm tin, thái độ và các kỹ năng mà mỗi cá nhân có được trong quá trình giáo dục ở gia đình và nhà trường" (Small, Harding, \& Lamont, 2010, p. 18). Sự khác biệt về vốn văn hóa sẽ đặt để mỗi cá nhân vào từng vị trí xã hội khác nhau trong thang bậc của xã hội. Như vậy, những người có vốn văn hóa thấp sẽ đưa đến việc họ cũng có vốn kinh tế và vốn xã hội thấp khiến họ không thể cạnh tranh được trong nền kinh tế vốn ngày càng cạnh tranh khốc liệt và đòi hỏi nhiều tri thức cũng như kỹ năng.

Hai lối nhìn về nghèo đói như vừa nêu trên là mang tính chất vi mô (microlevel), trong khi 
lối giải thích cấu trúc về nghèo đói (strutural explanation) lại mang tính vĩ mô (macrolevel). Trong lối nhìn này, nghèo đói không phải là kết quả của những yếu tố thuộc về cá nhân như lười biếng, sức khỏe hay sự thiếu vốn văn hóa nhưng nghèo đói là kết quả của những bất bình đẳng trong xã hội. Có nghĩa là người nghèo không phải là người chịu trách nhiệm chính về sự nghèo đói của họ bởi chính sự trục trặc trong cấu trúc xã hội tạo ra nghèo đói. Trong nhãn quan Mác-xít (Marxism), nghèo đói là hệ quả tất yếu của hệ thống kinh tế tư bản chủ nghĩa bởi trong hệ thống kinh tế này, toàn bộ giá trị thặng dư đều lọt vào tay của người chủ sở hữu các phương tiện sản xuất. Do đó, đồng lương của người lao động không tăng tương ứng với giá trị thặng dư do sức lao động của họ làm ra và điều này khiến họ sống trong tình trạng nghèo đói (Peet, 1975, p. 566).

Như vậy trong lối nhìn mang tính cấu trúc, nghèo đói là kết quả của sự bất công trong xã hội, tức các cơ hội thăng tiến không được phân bố đồng đều cho mọi người; và nghèo đói còn là kết quả của những bất bình đẳng về kinh tế khi người lao động không được trả lương tương xứng với sức lao động mà họ bỏ ra, cũng như sự phân bố nguồn tài nguyên, sự giàu có không đồng đều trong xã hội (Hunt, 1996, p. 298).

\section{Phương pháp nghiên cứu: Bộ tiêu chí đo lường}

Đề tài này không nhằm mục tiêu phân tích hiện tượng nghèo cũng như các yếu tố giải thích cho hiện tượng nghèo đói trong xã hội mà chỉ khám phá cách nhìn nhận của sinh viên về vấn đề nghèo đói trong xã hội.

Đo lường nhận thức về nghèo đói nơi các cá nhân trong xã hội nói chung và các sinh viên đang theo học ngành CTXH là điều rất cần thiết. Như Atherton và cộng sự (1993) đã lưu ý: "Các nhà nghiên cứu CTXH cần có một cách thức đo đáng tin cậy về thái độ đối với vấn đề nghèo đói và về nhũng người nghèo trong xã hội. Bên cạnh các úng dụng cho nghiên cứu, NVCTXH có thể sủ dụng thang đo đáng tin câyy để xác định các vấn đề trong các hội thảo chuyên nghiệp liên quan đến thái độ đối với nghèo đói và người nghèo. Các giảng viên CTXH có thể sủ dụng thang đo để đánh giá thái độ, nhận thức của sinh viên đối với vấn đề nghèo đói và nguời nghèo khi các em giải quyết các câu hỏi giá trị liên quan đến nghèo đói." (Atherton et al, 1993, p. 1).

Và trong đánh giá thái độ, nhận thức đối với nghèo đói, Feagin (1972) được xem như là một trong những người đầu tiên có công trong việc phát triển công cụ đo lường nhận thức, thái độ của cá nhân về các nguyên nhân của nghèo đói (Sun, 2001, p. 164). Công cụ này được đặt tên là "Thang đo nghèo đói của Feagin" (Feagin Poverty Scale). Thang đo này bao gồm 11 phát biểu (items) thể hiện ba cách lý giải về nguyên nhân của nghèo đói đó là: cá nhân (invidualistic), cấu trúc (structural) và định mệnh/số phận (fatalistic). Hai lối giải thích cá nhân và cấu trúc đã được trình bày bên trên, trong khi lối lý giải nghèo đói như là một định mệnh xem nghèo đói như là điều không may xảy đến với cá nhân như các vụ thiên tai, dịch bệnh hay chiến tranh.

Dựa trên thang đo nghèo đói của của Feagin vốn bị cho là không toàn diện và có những câu hỏi thiếu hiệu lực (validity), Yun và Weaver (2010) đã xây dựng một phiên bản ngắn (short form) để đo lường thái độ đối với nghèo đói gọi là "Attitude toward Poverty Short form, " (ATP$S F$ ). Bộ tiêu chí này bao gồm 21 items, trong đó "các yếu tố cá nhân" (personal deficiency) có 7 item, "các yếu tố mang tính kỳ thị" (stigma) gồm 8 item và "các yếu tố mang tính cấu trúc" (structural perspective) gồm 6 item. Mỗi item được cho điểm theo thang đo Likert từ 1 đến 5.

Tuy nhiên, Blair, Brown, Schoepflin, và Taylor (2014) cho rằng các bộ tiêu chí đo lường nhận thức và thái độ đối với nghèo đói và người nghèo như trên đã không đo lường một yếu tố rất quan trọng đó là "sụ thấu cảm" (empathy) đối với người nghèo. Theo các tác giả này, tầm quan trọng của sự thấu cảm liên quan đến tính sẵn sàng trợ giúp người nghèo là điều đã được chấp nhận trong giới nghiên cứu về nghèo đói. Từ đó, nhóm tác giả này đã đưa ra bộ tiêu chí đo lường "Nhận 
thức của sinh viên về nghèo" (The Undergraduate Perceptions of Poverty Tracking Survey UPPTS) gồm 39 item được phân thành ba nhóm gồm: thái độ chung về người nghèo, sự thấu cảm đối với người nghèo và sự cam kết giải quyết vấn đề nghèo đói thông qua hành động trực tiếp hoặc việc hỗ trợ các chương trình/dịch vụ giúp đỡ người nghèo.

Bên cạnh đó, Shek (2003) đã phát triển bộ tiêu chí đo lường riêng để đánh giá nhận thức của sinh viên Trung Quốc về nghèo đói. Bộ tiêu chí "Cái nhìn của Trung Quốc về các nguyên nhân của nghèo đói" (the Chinese Perceived Causes of Poverty scale - CPCPS) bao gồm 13 item chia thành bốn nhân tố là: các vấn đề cá nhân của người nghèo, sự bóc lột, thiếu cơ hội và số phận. Do có sự tương đồng về văn hóa, chúng tôi nhận thấy bộ tiêu chí này khá phù hợp với Việt Nam. Tuy nhiên, số lượng phát biểu/đề mục cho từng nhân tố lại khá ít.

Do đó, trong đề tài này, chúng tôi kết hợp nhiều bộ tiêu chí như vừa nêu trên để hình thành tiêu chí đo lường riêng cho Việt Nam.

Như vậy, phương pháp được sử dụng phương pháp nghiên cứu định lượng để tìm hiểu nhận thức của sinh viên về nghèo đói xem liệu các sinh viên nhìn nghèo đói như là kết quả của những yếu tố cá nhân, văn hóa, cấu trúc hay định mệnh hoặc họ đều cho rằng cả ba yếu tố này đều là những yếu tố quan trọng như nhau trong vấn đề nghèo đói.

Đề tài sử dụng phương pháp thu thập thông tin bằng điều tra xã hội học qua bảng hỏi soạn sẵn và phân tích dữ liệu bằng phương pháp thống kê qua phần mềm SPSS.

\section{Khách thể, đối tượng, phạm vi nghiên cứu}

\section{1. Đối tự̛ng nghiên cúu}

Đề tài nghiên cứu nhận thức về vấn đề nghèo đói, các nguyên nhân dẫn đến tình trạng nghèo đói trong xã hội của các sinh viên đang học ngành CTXH trong so sánh với sinh viên của các ngành học khác tại trường Đại học Mở Thành phố Hồ Chí Minh.

\subsection{Khách thể nghiên cúu}

Khách thể của cuộc nghiên cứu này là các sinh viên đang học ngành $\mathrm{CTXH}$ và sinh viên của ba ngành Kinh tế, Ngoại ngữ và Luật đang theo học từ năm thứ hai trở lên tại trường Đại học Mở Thành phố Hồ Chí Minh. Chúng tôi chọn nghiên cứu các sinh viên từ năm thứ hai trở đi là vì các sinh viên này đã trải qua một năm học các môn học đại cương và đã bắt đầu vào học các môn học chuyên sâu. Do đó, chọn các sinh viên học từ năm thứ hai sẽ giúp đo lường chính xác hơn các quan điểm, nhận thức của họ về vấn đề nghèo đói.

Mẫu khảo sát gồm 180 sinh viên, trong đó có 86 sinh viên CTXH và 94 sinh viên của ba ngành khác. Phương pháp chọn mẫu là phi xác suất với loại mẫu tiện lợi (accidential sampling).

\section{Kết quả nghiên cứu}

\section{1. Đặc điểm mẫu nghiên cúu}

Như đã trình bày bên trên, đề tài tiến hành nghiên cứu trên một mẫu gồm 180 sinh viên, trong đó số sinh viên thuộc ngành CTXH là 86 (47,8\%), sinh viên ngành Luật là 34 (18,9\%), sinh viên ngành Kinh tế là $30(16,7 \%)$ và sinh viên ngành Ngoại ngữ cũng là $30(16,7)$. Như vậy, số sinh viên ngành $\mathrm{CTXH}$ chiếm tỷ lệ là $47,8 \%$ và sinh viên ba ngành còn lại chiếm tỷ lệ $52,2 \%$. Hai tỷ lệ này được xem là tương đương nhau và có thể so sánh được với nhau. Chi tiết đặc điểm mẫu nghiên cứu được thể hiện ở Bảng 1 dưới đây: 


\section{Bảng 1}

Đặc điểm mẫu nghiên cứu (theo \%)

\begin{tabular}{|c|c|c|c|}
\hline \multirow{2}{*}{ Biến } & & \multicolumn{2}{|c|}{ Nhóm sinh viên } \\
\hline & & СТХН & Ngành khác \\
\hline \multirow{2}{*}{ Giới tính } & - Nam & 17,4 & 28,7 \\
\hline & - Nữ & 82,6 & 71,3 \\
\hline \multirow{2}{*}{ Năm học Đại học } & - Năm thứ 2 & 47,7 & 68,1 \\
\hline & - Năm thứ 3 & 52,3 & 31,9 \\
\hline \multirow{2}{*}{ Nguyện vọng vào Đại học Mở } & - NV 1-2 & 68,2 & 81,3 \\
\hline & - NV 3 trở lên & 31,8 & 18,7 \\
\hline \multirow{5}{*}{ Nơi ở trước khi vào Đại học } & $\begin{array}{l}\text { - Thành phố Hồ Chí } \\
\text { Minh }\end{array}$ & 38,4 & 22,3 \\
\hline & - Đông Nam bộ & 14,0 & 17,0 \\
\hline & - Tây Nam bộ & 12,8 & 9,6 \\
\hline & - Trung-Tây nguyên & 32,6 & 47,9 \\
\hline & - Miền Bắc & 2,2 & 3,2 \\
\hline \multirow{3}{*}{ Kinh tế gia đình } & - Giàu-khá & 32,4 & 34,0 \\
\hline & - Trung bình & 57,0 & 63,8 \\
\hline & - Nghèo & 10,5 & 2,1 \\
\hline \multirow{3}{*}{ Xếp loại học lực học kỳ gần nhất } & - Giỏi & 5,9 & 13,2 \\
\hline & - Khá & 63,5 & 63,7 \\
\hline & - TB-TBK & 30,6 & 23,1 \\
\hline $\begin{array}{l}\text { Tuổi trung bình } \\
\text { Độ lệch chuẩn }\end{array}$ & & $\begin{array}{l}20,6 \\
1,12\end{array}$ & $\begin{array}{l}20,4 \\
0,56\end{array}$ \\
\hline
\end{tabular}

Nguồn: Kết quả phân tích cuộc điều tra của tác giả vào tháng 08/2020

Bên cạnh các yếu tố như trong bảng dữ liệu trên, đề tài cũng thu thập các thông tin về dân tộc gia đình có thuộc diện chính sách hay không. Kết quả phân tích dữ liệu cho thấy chỉ có $6,7 \%$ số sinh viên cho biết họ thuộc diện gia đình chính sách; về yếu tố dân tộc, có đến $97,2 \%$ là dân tộc Kinh. Hai yếu tố này quá chênh lệch nên sẽ không được đưa vào phân tích như những biến số độc lập.

\subsection{Sỵ thích hợp của thang đo}

Như đã trình bày, đề tài này sử dụng lại các bộ tiêu chí đo lường nhận thức về nghèo của các tác giả Yun và Weaver (2010) cũng như Atherton và cộng sự (1993) và có điều chỉnh lại cho phù hợp với bối cảnh của Việt Nam. Bộ tiêu chí bao gồm 44 item nhằm đo lường nhận thức của sinh viên về nghèo đói theo các lối nhìn như trong bảng sau: 


\section{Bảng 2}

Các quan niệm về nghèo đói và người nghèo

\begin{tabular}{|l|c|}
\hline \multicolumn{1}{|c|}{ Các quan niệm } & Số lượng item \\
\hline 1. Những khiếm khuyết thuộc về cá nhân người nghèo & 9 \\
\hline 2. Lối nhìn gán nhãn, phân biệt đối xử đối với người nghèo & 13 \\
\hline 3. Lối nhìn mang tính cấu trúc về nghèo đói & 6 \\
\hline 4. Nghèo do bị bóc lột & 3 \\
\hline 5. Nghèo do thiếu cơ hội, kỹ năng & 9 \\
\hline 6. Sự thấu cảm với nghèo đói và người nghèo & 4 \\
\hline Tổng & $\mathbf{4 4}$ \\
\hline
\end{tabular}

Nguồn: Kết quả phân tích cuộc điều tra của tác giả vào tháng 08/2020

Trong bộ tiêu chí đo lường này, mỗi một item được đo theo thang đo Likert-5 điểm mà theo đó, điểm $1=$ hoàn toàn đồng ý và $5=$ hoàn toàn không đồng ý. Như vậy điểm tối đa của toàn bộ bộ tiêu chí đo lường là 200 và điểm nhỏ nhất là 44, tức là điểm càng nhỏ thì mức độ đồng ý với các định đề càng cao và ngược lại.

Đề tài đã tiến hành phân tích độ tin cậy Cronbach’s Alpha cho các item thuộc sáu loại quan niệm về nghèo đói/người nghèo. Kết quả như sau:

\section{Bảng 3}

Kết quả phân tích Cronbach Alpha

\begin{tabular}{|l|c|}
\hline \multicolumn{1}{|c|}{ Các quan niệm } & Hệ số Cronbach's Alpha \\
\hline 1. Những khiếm khuyết thuộc về cá nhân người nghèo & 0,910 \\
\hline 2. Lối nhìn gán nhãn, phân biệt đối xử đối với người nghèo & 0,793 \\
\hline 3. Lối nhìn mang tính cấu trúc về nghèo đói & 0,627 \\
\hline 4. Nghèo do bị bóc lột & 0,670 \\
\hline 5. Nghèo do thiếu cơ hội, kỹ năng & 0,753 \\
\hline 6. Sự thấu cảm với nghèo đói và người nghèo & 0,690 \\
\hline
\end{tabular}

Nguồn: Kết quả phân tích cuộc điều tra của tác giả vào tháng 08/2020

Nhiều nhà nghiên cứu đồng ý rằng khi Cronbach's Alpha từ 0,8 đến gần 1,0 thì thang đo lường là tốt, từ 0,7 đến gần 0,8 là dùng được. Cũng có nhà nghiên cứu đề nghị rằng Cronbach's Alpha từ 0,6 trở lên là có thể sử dụng được trong trường hợp khái niệm đang đo lường là mới hoặc mới đối với người trả lời trong bối cảnh nghiên cứu (Hoang \& Chu, 2008). Như vậy toàn bộ các item được dùng trong bộ tiêu chí này được phân ra thành sáu nhóm tương ứng với sáu lối nhìn về người nghèo và sự nghèo đói đều có thể được sử dụng vì đây là bộ tiêu chí lần đầu tiên được dùng trong nghiên cứu tại Việt Nam.

\subsection{Nhận diện quan niệm của sinh viên về nghèo đói và người nghèo}

Kết quả phân tích dữ liệu về sáu lối nhìn về người nghèo đói và người nghéo cho thấy phần lớn sinh viên nói chung trong mẫu nghiên cứu xem nguyên nhân của nghèo đói là do các yếu tố 
nằm bên ngoài cá nhân, tức là xem những yếu tố thuộc về cấu trúc như thiên tai, dịch bệnh, sự phân phối thu nhập không công bằng và nói chung là do sự thiếu công bằng xã hội như bảng dữ liệu sau:

\section{Bảng 4}

Điểm trung bình và độ lệch chuẩn của các item

\begin{tabular}{|c|c|c|}
\hline Item & $\begin{array}{l}\text { Điểm trung } \\
\text { bình }\end{array}$ & $\begin{array}{l}\text { Độ lệch } \\
\text { chuẩn }\end{array}$ \\
\hline \multicolumn{3}{|l|}{ A. Những khiếm khuyết thuộc về cá nhân người nghèo } \\
\hline 1. Người nghèo khác với phần còn lại trong xã hội & 3,74 & 0,9 \\
\hline 2. Người nghèo không trung thực & 4,39 & 0,72 \\
\hline 3. Hầu hết người nghèo đều dơ bẩn & 4,56 & 0,67 \\
\hline 4. Người nghèo có ửng xử không giống mọi người & 4,16 & 0,87 \\
\hline $\begin{array}{l}\text { 5. Trẻ em được nuôi dưỡng nhờ trợ cấp xã hội sẽ không bao giờ đạt } \\
\text { được thành công gì cả }\end{array}$ & 4,60 & 0,55 \\
\hline 6. Tôi tin rằng người nghèo có một hệ giá trị khác với mọi người & 2,92 & 1,17 \\
\hline 7. Nói chung, người nghèo kém thông minh hơn người không nghèo & 4,34 & 0,78 \\
\hline 8. Đa số người nghèo thuộc các dân tộc thiểu số & 3,20 & 1,04 \\
\hline 9. Phần lớn người nghèo là phụ nữ & 4,08 & 0,93 \\
\hline \multicolumn{3}{|l|}{ B. Lối nhìn gán nhãn, phân biệt đối xử đối với người nghèo } \\
\hline 10. Có nhiều sự gian lận nơi những người nhận trợ cấp/phúc lợi xã hội & 2,53 & 0,86 \\
\hline $\begin{array}{l}\text { 11. Một số người nghèo có cuộc sống tốt hơn tôi khi xem xét toàn bộ các } \\
\text { lợi ích mà họ được hưởng }\end{array}$ & 3,12 & 0,87 \\
\hline 12. Người nghèo nghĩ rằng họ xứng đáng được hỗ trợ/trợ cấp & 2,87 & 0.86 \\
\hline 13. Người nghèo được hưởng nhiều ưu đãi nên họ không muốn thoát nghèo & 3,26 & 1,04 \\
\hline $\begin{array}{l}\text { 14. Người khỏe mạnh hưởng trợ cấp xã hội làm hủy hoại hệ thống phúc } \\
\text { lợi }\end{array}$ & 3,07 & 1,08 \\
\hline 15. Người nghèo thiếu khả năng quản lý tài chính & 3,25 & 1,02 \\
\hline 16. Người nghèo lãng phí tiền của họ cho những thứ không cần thiết & 3,74 & 0,88 \\
\hline 17. Người nghèo không có động lực cải thiện cuộc sống của bản thân & 3,73 & 0,88 \\
\hline $\begin{array}{l}\text { 18. Những người nghèo thất nghiệp có thể kiếm được việc làm nếu họ cố } \\
\text { gắng hơn }\end{array}$ & 2,23 & 1,00 \\
\hline 19. Trợ cấp/phúc lợi xã hội làm cho con người ta trở nên lười biếng & 2,92 & 0,97 \\
\hline 20. Lợi ích dành cho người nghèo chiếm phần đáng kể ngân sách quốc gia & 3,03 & 0,77 \\
\hline 21. Người nghèo hài lòng với việc được nhận trợ cấp & 2,94 & 0,84 \\
\hline 22. Tôi nghĩ người nghèo tự tạo ra khó khăn cho chính họ & 3,41 & 0,96 \\
\hline
\end{tabular}




\begin{tabular}{|c|c|c|}
\hline Item & $\begin{array}{c}\text { Điểm trung } \\
\text { bình }\end{array}$ & $\begin{array}{l}\text { Độ lệch } \\
\text { chuẩn }\end{array}$ \\
\hline \multicolumn{3}{|l|}{ C. Lối nhìn mang tính cấu trúc về nghèo đói } \\
\hline $\begin{array}{l}\text { 23. Người ta nghèo là do những hoàn cảnh (thiên tai, dịch bệnh...) nằm } \\
\text { ngoài sự kiểm soát của họ }\end{array}$ & 2,71 & 1,07 \\
\hline $\begin{array}{l}\text { 24. Tôi sẽ ủng hộ việc đánh thuế cao hơn để có tiền cho các chương trình } \\
\text { xã hội trợ giúp người nghèo }\end{array}$ & 3,34 & 0,99 \\
\hline 25. Nếu tôi nghèo, tôi sẵn sàng nhận trợ cấp xã hội dành cho người nghèo & 2,54 & 0,88 \\
\hline 26. Không nên đổ lỗi cho người nghèo & 1,92 & 0,87 \\
\hline 27. Xã hội có trách nhiệm giúp đỡ người nghèo & 2,45 & 0,93 \\
\hline 28. Các doanh nghiệp/công ty nên giúp người nghèo nhiều hơn & 2,45 & 0,88 \\
\hline \multicolumn{3}{|l|}{ D. Nghèo do bị bóc lột } \\
\hline 29. Người nghèo bị người giàu bốc lột & 3,04 & 1,05 \\
\hline 30. Nền văn hóa của chúng ta thiếu sự công bằng xã hội & 2,46 & 1,03 \\
\hline 31. Xã hội chúng ta phân phối thu nhập không đồng đều & 2.08 & 0,88 \\
\hline \multicolumn{3}{|l|}{ C. Nghèo do thiếu cơ hội, kỹ năng } \\
\hline 32. Người nghèo thiếu cơ hội bởi vì họ sống trong gia đình nghèo & 2,60 & 1,16 \\
\hline 33. Người nghèo sống ở những vùng không có nhiều cơ hội phát triển & 2,35 & 0,93 \\
\hline $\begin{array}{l}\text { 34. Người nghèo đã trải qua những điều bất hạnh (làm hạn chế cơ hội của } \\
\text { họ) }\end{array}$ & 2,47 & 0,90 \\
\hline 35. Người nghèo bị phân biệt đối xử & 2,31 & 0,89 \\
\hline 36. Thiếu học vấn là một thách thức lớn đối với người nghèo & 1,70 & 0,62 \\
\hline 37. Thiếu sự hỗ trợ xã hội là một thách thức lớn đối với người nghèo & 2,45 & 0,81 \\
\hline $\begin{array}{l}\text { 38. Con cái không được chăm sóc sức khỏe là một thách thức lớn đối với } \\
\text { người nghèo }\end{array}$ & 2.02 & 0,75 \\
\hline 39. Thiếu phương tiện đi lại là một thách thức lớn đối với người nghèo & 2,45 & 0.90 \\
\hline 40. Thiếu tay nghề là một thách thức đối với người nghèo & 2,11 & 0,82 \\
\hline \multicolumn{3}{|l|}{ D. Sự thấu cảm với nghèo đói và người nghèo } \\
\hline 41. Tôi nghĩ rằng tôi biết thế nào là nghèo & 2,48 & 0,78 \\
\hline $\begin{array}{l}\text { 42. Tôi nghĩ rằng tôi đã tiếp xúc trực tiếp đủ (không nhiều/không ít) với } \\
\text { người nghèo }\end{array}$ & 2,60 & 0,82 \\
\hline $\begin{array}{l}\text { 43. Tôi nghĩ rằng tôi biết lý do khiến một ai đó có thể bị rơi vào cảnh } \\
\text { nghèo (kinh tế) }\end{array}$ & 2,55 & 0,76 \\
\hline 44. Tôi từng bàn luận về vấn đề nghèo đói với người khác & 2,49 & 0,97 \\
\hline
\end{tabular}

$1=$ hoàn toàn đồng ý; $5=$ hoàn toàn không đồng ý

Nguồn: Kết quả phân tích cuộc điều tra của tác giả vào tháng 08/2020 
Vậy liệu có sự khác biệt trong nhận diện về nguyên nhân nghèo đói nơi nhóm sinh viên CTXH với các sinh viên thuộc các ngành khác vốn không được đào tạo sâu về các vấn đề xã hội? Kết quả phân tích cho thấy có sự khác biệt giữa hai nhóm sinh viên trong bốn quan niệm về nghèo đói và kết quả này rất đáng quan tâm. Nhóm sinh viên CTXH đồng ý nhiều hơn với quan niệm xem nghèo đói xuất phát từ những khiếm khuyết, những yếu kém của cá nhân người nghèo $(3,85$ so với 4,13). Có lẽ vì chương trình đào tạo ngành $\mathrm{CTXH}$ thường đề cập và thực hành môn " $\mathrm{CTXH}$ cá nhân" mà theo đó, người nhân viên CTXH xem các cá nhân yếu thế (tức "thân chủ" theo thuật ngữ của ngành này) có nhiều tiềm năng nhưng không được khai thác, vận động để phát huy nên khiến các sinh viên CTXH xem nghèo như là kết quả của những khiếm khuyết cá nhân nhiều hơn. Tuy nhiên, cả hai nhóm đều có cái nhìn tương đồng đó là đều có mức độ đồng ý cao với các quan niệm xem nghèo xuất phát từ các nguyên nhân mang tính cấu trúc, nghèo do sự bóc lột, sự thiếu công bằng trong xã hội và cả hai nhóm đều có sự thấu cảm cao với người nghèo và sự nghèo đói trong xã hội (Bảng 5).

\section{Bảng 5}

Kiểm định t-test về sự khác biệt giữa hai nhóm

\begin{tabular}{|l|c|c|c|}
\hline \multicolumn{1}{|c|}{ Các quan niệm } & \multicolumn{2}{c|}{ Điểm trung bình } & \\
\hline & CTXH & Ngành khác & P \\
\hline 1. Những khiếm khuyết thuộc về cá nhân người nghèo & 3,85 & 4,13 & 0,000 \\
\hline 2. Lối nhìn gán nhãn, phân biệt đối xử đối với người nghèo & 2,90 & 3,25 & 0,000 \\
\hline 3. Lối nhìn mang tính cấu trúc về nghèo đói & 2,60 & 2,54 & n.s \\
\hline 4. Nghèo do bị bóc lột & 2,23 & 2,79 & 0,000 \\
\hline 5. Nghèo do thiếu cơ hội, kỹ năng & 2,15 & 2,38 & 0,002 \\
\hline 6. Sự thấu cảm với nghèo đói và người nghèo & 2,48 & 2,57 & n.s \\
\hline
\end{tabular}

Nguồn: Kết quả phân tích cuộc điều tra của tác giả vào tháng 08/2020

\section{Thảo luận và kết quả}

Mục tiêu chính của đề tài này khám phá quan niệm về nghèo đói và người nghèo của sinh viên ngành $\mathrm{CTXH}$, vốn được đào tạo để làm việc với những nhóm người yếu thế trong xã hội với sinh viên các ngành khác để xem coi có sự khác biệt có ý nghĩa hay không. Nhìn chung, cái nhìn của sinh viên $\mathrm{CTXH}$ về nghèo đói và người nghèo cũng khá tương đồng với những nghiên cứu trước đây của các tác giả ngoài nước, chẳng hạn như nghiên cứu của Hamilton và Daughtry (2017) cho thấy mức độ đồng ý nơi các sinh viên CTXH tăng dần với hai quan niệm nghèo đói xuất phát từ những khiếm khuyết cá nhân và cũng có nguyên nhân từ cấu trúc xã hội. Nghiên cứu của Hunt (1996) cũng cho thấy nhiều sinh viên ở Mỹ cũng xem nghèo đói như là kết quả của những yếu tố cá nhân cũng như các yếu tố thuộc cấu trúc xã hội. Kết quả nghiên cứu so sánh giữa sinh viên ngành CTXH với các sinh viên thuộc các ngành khác thuộc các trường đại học vùng Tây Nam của Mỹ cũng cho thấy sinh viên CTXH dù cũng đánh giá các nguyên nhân mang tính mang tính cá nhân là quan trọng nhưng không quan trọng bằng các nguyên nhân mang tính cấu trúc của nghèo đói, trong khi các sinh viên thuộc các ngành khác lại cho rằng hai nguyên nhân này có tầm quan trọng như nhau (Sun, 2001, p. 169).

Kết quả so sánh các quan niệm về nghèo đói giữa hai nhóm sinh viên (Bảng 5) cho thấy chúng khá phù hợp với những mục tiêu, giá trị hướng đến của việc đào tạo nghề công tác xã hội. Sở dĩ như thế là vì trong chương trình đào tạo của ngành học này, các sinh viên $\mathrm{CTXH}$ được đào 
tạo nhiều về công tác xã hội cá nhân mà theo đó, người nhân viên CTXH cần giúp cho thân chủ của mình tăng khả năng huy động những nguồn lực của bản thân và của xã hội nhằm tạo sự thay đổi cho chính mình. Môn phát triển cộng đồng (community development) nhằm "làm chuyển biến cộng đồng nghèo, thiếu tụ tin thành cộng đồng tụ lực thông qua việc giáo dục gây nhận thức về tình hình, vấn đề hiện tại của họ, phát huy các khả năng và tài nguyên sã̃n có, tổ chức các hoạt động tư giúp, bồi dương và củng cố tổ chức, và tiến tới tụ lực, phát triển” (T. M. H. Le, 2018) cũng là một trong những nội dung chính của việc đào tạo ngành công tác xã hội.

Qua kết quả nghiên cứu của đề tài này, chúng tôi đề xuất một số nội dung cho việc đào tạo CTXH tại trường như sau:

- Nên xác định rõ hơn khái niệm nghèo đói, sự loại trừ xã hội, sự gán nhãn và ra mối liên hệ của chúng với CTXH;

- Gia tăng sự hiểu biết về nghèo đói và những tác động lâu dài của nó đến cá nhân và gia đình nơi sinh viên CTXH;

- Xác định rõ hơn những cách thức hữu hiệu mà người nhân viên $\mathrm{CTXH}$ có thể sử dụng trong việc ứng phó với tình trạng nghèo và hỗ trợ người nghèo trong xã hội;

- Nâng cao nhận thức của sinh viên CTXH về tầm quan trọng của công bằng xã hội, việc tạo sự bình đẳng về cơ hội như là một trong những giải pháp xóa đói giảm nghèo bền vững.

Đây là đề tài nghiên cứu đầu tiên ở Việt Nam về nhận thức của sinh viên CTXH trong so sánh với sinh viên các ngành khác về tình trạng nghèo đói và người nghèo trong xã hội, do đó đề tài chắc chắn có những hạn chế. Trước hết là mẫu nghiên cứu chưa đủ lớn nên có thể kết quả chưa phản ánh cách chính xác nhất nhận thức của sinh viên về vấn đề nghèo đói và người nghèo trong xã hội. Một nghiên cứu với mẫu nghiên cứu lớn hơn bao gồm các sinh viên thuộc nhiều dân tộc khác nhau có thể sẽ cho ra một kết quả thuyết phục hơn.

\section{Tài liệu tham khảo}

Atherton, C. R., Gemmel, R. J., Haagenstad, S., \& Holt, D. J. (1993). Measuring attitudes toward poverty: A new scale. Social Work Research \& Abstracts, 29(4), 28-30.

Benicourt, E. (2001). La pauvreté selon le PNUD et la Banque mondiale [Poverty according to the UNDP and the World Bank]. Études Rural, 159-160, 35-54. doi:10.4000/etudesrurales.68.

Blair, K. D., Brown, M., Schoepflin, T., \& Taylor, D. B. (2014). Validation of a tool to assess and track undergraduate attitudes toward those living in poverty. Research on Social Work Practice, 24(4), 448-461. doi:10.1177/1049731513497404

Castillo, J. T., \& Becerra, D. (2012). The perception of poverty and social welfare policies among undergraduate and graduate social work students in the United States. Journal of Human Behavior in the Social Environment, 22(4), 375-391. doi:10.1080/10911359.2012.664499

Chính phủ. (2015). Quyết định số 59/2015/QĐ-TTg về việc ban hành chuẩn nghèo tiếp cận đa chiều áp dụng cho giai đoạn 2016-2020 [Decision No. 59/2015 / QD-TTg on promulgating multidimensional poverty lines applicable for the period 2016-2020]. Retrieved October 10, 2020, from: http://vanban.chinhphu.vn/portal/page/portal/chinhphu/hethongvanban?class_id $=1 \& \_$page $=1 \&$ mode $=$ detail $\&$ document_id=182199.

Clark, S. (2007). Social work students' perceptions of poverty. Journal of Human Behavior in the Social Environment, 16(1/2), 149-166. doi:10.1300/J137v16n01_10 
Công tác xã hội. (2019). Công tác xã họi là gì? [What is social work?]. Retrieved January 20, 2019, from https://congtacxahoi.net/cong-tac-xa-hoi-la-gi/

Cozzarelli, C., Wilkinson, A. V., \& Tagler, M. J. (2001). Attitudes toward the poor and attributions for poverty. Journal of Social Issues, 57(2), 207-227. doi:10.1111/0022-4537.00209

Cryns, A. G. (1977). Social work education and student ideology: A multivariate study of professional socialization. Journal of Education for Social Work, 13(1), 44-51. doi:10.1080/00220612.1977.10671412

Dang, T. T. T. (2013). Nhận thức hành vi nghề nghiệp của nhân viên xã hội. Nghiên cúu tại Trung tâm Bảo trợxã họi tỉnh Lâm Đồng và Trung tâm 05-06 [Recognize the professional behavior of social workers. Research at Lam Dong Social Protection Center and Center 05-06] (Unpublished master's thesis). University of Social Sciences and Humanities, Hanoi, Vietnam.

Feagin, J. R. (1972). Poverty: We still believe that God helps those who help themselves. Psychology Today, 6, 101-129.

Hamilton, L., \& Daughtry, L. (2017). Student attitudes toward poverty in a social welfare policy course: Online versus face to face. SAGE Open, 7(2), 1-4. doi:10.1177/2158244017709326

Hill, K. M., Toft, J. E., Garrett, K. J., Ferguson, S. M., \& Kuechler, C. F. (2016). Assessing clinical MSW students' attitudes, attributions, and responses to poverty. Journal of Poverty, 20(4), 396-416. doi:10.1080/ 10875549.2015.1105345.

Hoang, T., \& Chu, N. M. N. (2008). Phân tích dũ liệu nghiên cúu với SPSS [Analysis of research data with SPSS]. Ho Chi Minh, Vietnam: NXB Hồng Đức.

Hunt, M. O. (1996). The individual, society or both? A comparison of Black, Latino and White beliefs about the causes of poverty. Social Forces, 75(1), 293-322. doi:10.2307/2580766

International Federation of Social Workers (IFSW). (2014). Global definition of social work. Retrieved January 20, 2019, from https://www.ifsw.org/what-is-social-work/globaldefinition-of-social-work/

Le, T. M. H. (2018). Phát triển cộng đồng [Community development]. Ho Chi Minh, Vietnam: Trường Đại học Mở Thành phố Hồ Chí Minh.

Le, T. T. (2016). Nhận thức của sinh viên ngành công tác xã hội về tiếp cận và huy động nguồn lục công đồng [Social work students' awareness of community resource access and mobilization]. Retrieved November 15, 2018, from: http://ulsa.edu.vn/NewsDetail.aspx?ID=1707.

Lewis, O. (1978). Les enfants de Sanchez: Autobiographie d'une famille mexicaine [Sanchez's children: Autobiography of a Mexican family. Paris, France: Gallimard.

Monnickendam, M. (2010). Poverty perceptions of social workers and physicians in Israel. Social Work in Health Care, 49(10), 963-980. doi:10.1080/00981389.2010.518877

National Association of Social Workers (NASW). (2017). Read the code of ethics. Retrieved January 20, 2019, from https://www.socialworkers.org/about/ethics/code-of-ethics/code-ofethics-english

Osgood, M. H. (1977). Rural and urban attitudes toward welfare. Social Work, 22(1), 41-47.

Peet, R. (1975). Inequality and poverty: A Marxist-geographic theory. Annals of the Association of American Geographers, 65(4), 564-571. doi:10.1111/j.1467-8306.1975.tb01063.x 
Phillips, E. L. (1994). Diploma nursing students' attitudes toward poverty (Master's thesis). Grand Valley State University, Allendale, MI.

Rank, M. R. (1994). A view from the inside out: Recipient's perceptions of welfare. Journal of Sociology and Social Welfare, 21(2), 27-47.

Reeser, L. C., \& Epstein, I. (1987). Social workers' attitudes toward poverty and social action 1968-1984. Social Service Review, 61(4), 610-622. doi:10.1086/644481

Rehner, T., Ishee, J., Salloum, M., \& Velasques, D. (1997). Mississippi social workers' attitudes toward poverty and the poor. Journal of Social Work Education, 33(1), 131-142.

Roark, E. (2004). Herbert Spencer's evolutionary individualism. Quarterly Journal of Ideology, 27(3/4), 1-31.

Rosenthal, B. S. (1993). Graduate social work student's beliefs about poverty and attitudes toward the poor. Journal of Teaching in Social Work, 7(1), 107-121. doi:10.1300/J067v07n01_09

Schwartz, S., \& Robinson, M. M. (1991). Attitudes toward poverty during undergraduate education. Journal of Social Work Education, 27(3), 290-296. doi:10.1080/10437797.1991.10672201

Shek, D. T. L. (2003). Chinese people's explanations of poverty: The perceived causes of poverty scale. Research on Social Work Practice, 13(5), 622-640. doi:10.1177/1049731503253376

Small, M. L., Harding, D. J., \& Lamont, M. (2010). Reconsidering culture and poverty. The ANNALS of the American Academy of Political and Social Science,629(1), 627. doi:10.1177/0002716210362077

Sun, A. P. (2001). Perceptions among social work and non-social work students concerning causes of poverty. Journal of Social Work Education, 37(1), 161-173. doi:10.1080/10437797.2001.10779044

Trường Đại học Mở Thành phố Hồ Chí Minh. (2017). Chuoong trình đào tạo [Curriculum]. Retrieved October 06, 2020, from http://ou.edu.vn/xhh/AnhHoatDong/Chuong\%20trinh \%20dao\%20tao/9.\%20DH_CTXH-2016.pdf

United Nations (UN). (n.d.). Ending poverty. Retrieved October 07, 2020, from https://www.un.org/en/global-issues/ending-poverty.

World Bank. (2003). Báo cáo phát triển Việt Nam 2004 - Nghèo [Vietnam development report 2004 - Poverty]. Retrieved January 20, 2019, from http://agro.gov.vn/vn/chitiet_nghiencuu.aspx?id=482

World Bank. (2015). FAQs: Global poverty line update. Retrieved October 07, 2020, from https://www.worldbank.org/en/topic/poverty/brief/global-poverty-linefaq\#: :targetText=As\%20of\%20October\%202015\%2C\%20the, at $\% 20 \% 241.90 \% 20$ using\% $202011 \% 20$ prices. Truy cập ngày 07-10-2020.

World Bank. (2018). Nghèo ở Việt Nam tiếp tục giảm [Poverty in Vietnam continues to decline]. Retrieved October 02, 2019, from: https://www.worldbank.org/vi/news/pressrelease/2018/04/05/vietnam-continues-to-reduce-poverty-according-to-world-bank-report

Yun, S. H., \& Weaver, R. D. (2010). Development and validation of a short form of the attitude toward poverty scale. Advances in Social Work, 11(2), 174-187. 